\title{
Effect of Occlusal Adjustment on Postoperative Pain after Root Canal Treatment:A Randomized Clinical Trial
}

\author{
Elizângela Cristina Barbosa Vianna ${ }^{10}$, Fernando José Herkrath ${ }^{2}{ }^{\circledR}$, Izabelly \\ Esteves Bittencourt Martins ${ }^{1 \oplus}$, Luana Pontes Barros Lopes ${ }^{1 \oplus}$, André Augusto \\ Franco Marques $^{1 \oplus}$, Emílio Carlos Sponchiado Júnior ${ }^{1}$
}

\author{
'Dental school, UFAM - Federal \\ University of Amazonas, \\ Manaus, AM, Brazil \\ ${ }^{2}$ Leônidas $\beta$ Maria Deane Institute, \\ Oswaldo Cruz Foundation, \\ Manaus, AM, Brazil \\ Correspondence: Emílio Carlos \\ Sponchiado Júnior, Rua Mins \\ Waldemar Pedrosa, n 1539, \\ 69025-050 Manaus, AM, Brasil. \\ Tel: +55-92-3305-4908. e-mail: \\ spemilio@ufam.edu.br
}

\begin{abstract}
The aim of this prospective, randomized, clinical study was to analyze the influence of occlusal adjustment on the prevalence of postoperative pain after endodontic treatment. Seventy-eight patients, diagnosed with symptomatic irreversible pulpitis with indication for endodontic treatment, were selected to participate in the study. The participants were randomized and divided into two groups: in the occlusal adjustment group (OAG), endodontic treatment was performed with subsequent occlusal adjustment. In the control group (CG), endodontic treatment was performed without occlusal adjustment. Treatments were performed by the same operator. Pain occurrence and intensity were recorded on two scales: the verbal rating scale (VRS) and numerical rating scale (NRS). Pain assessment was carried out by a second examiner, blinded to the experiment, 6, 24 and 72 $\mathrm{h}$ after endodontic treatment. Data were analyzed using Mann-Whitney, chi-squared, and Fisher's exact tests. In the occlusal adjustment group, 71.1\% reported postoperative pain and $67.5 \%$ reported pain in the control group. At the 6-hour assessment, 21 individuals reported pain in the occlusal adjustment group and 24 in the control group $(p=0.672)$. At the 24-hour assessment, 18 and 19 individuals reported pain $(p=0.991)$ and at the 72 -hour assessment, 8 and 4 reported pain $(p=0.219)$, respectively. Occlusal adjustment did not influence the prevalence of postoperative pain of endodontically treated teeth with symptomatic irreversible pulpitis.
\end{abstract}

Key Words: clinical trial, postoperative pain, endodontics, occlusal adjustments.

\section{Introduction}

The occurrence of postoperative pain is not a rare outcome after endodontic treatment. According to the systematic review by Sathorn et al. (1), it occurs in $3-58 \%$ of patients, being more common within the first $24 \mathrm{~h}$ and pain reducing to a minimum in 7 days.

Pain intensity following endodontic treatment is frequently mild to moderate, but it may be severe at times. Given the high frequency of postoperative pain, several studies have been carried out in an endeavour to seek treatments using different techniques, substances, instrumentation protocols, and photobiomodulation therapy to minimize pain occurrence (1-5). However, several aspects require elucidation; among them the role of occlusal adjustment after endodontic treatment (6-9). The cause of pain after endodontic treatment is multifactorial, which could be related to the procedures, instruments, medication, and substances used before, during, or after biomechanical preparation of the root canal system, as well as aspects related to the pulp or periapical pathology, which can play an important role in the development of postoperative pain $(1,3,10-13)$.

It is believed that one of the possible causes of pain after endodontic treatment may be the incidence of occlusal forces in the endodontically treated tooth area that would trigger mechanical allodynia and prolong postoperative pain. Mechanical allodynia can be defined as a reduction in pain threshold, whereas pain occurs in response to innocuous thermal and mechanical stimuli (14-19).

This mechanism is not well established, but it has been suggested that occlusal forces involving asensitized area with activation of pulp and periapical mechano receptive nociceptive neurons and pulp nociceptors may initiate mechanical allodynia $(15,16)$. Few studies have sought to assess the influence of occlusal adjustment on postoperative pain and its role is not clear in the literature. The few existing studies present inconsistent criteria that make it difficult to understand the role of occlusal adjustment for pain prevention and control. Aspects related to the research design concerning selection biases and confounders such as pulpal and periapical pathologies, endodontic instrumentation techniques, intracanal medication, calibration in case of multiple operators, and information on randomization, require further explanation for the results to be fully understood (6-9).

Thus, the aim of this study was to conduct a randomized, controlled, clinical study to assess the influence of occlusal adjustment on postoperative pain after endodontic 
treatment in teeth with symptomatic irreversible pulpitis.

\section{Material and Methods}

\section{Description of Trial Design}

The present study was approved by the Research Ethics Committee of the Federal University of Amazonas (CAAE $\left.n^{\circ} 58815116.1 .0000 .5020\right)$ and published in the Brazilian Registry of Clinical Trials - REBEC (UTN U1111-1187-0353). This is a randomized, controlled, double-blinded, parallelcontrolled clinical study. The study was conducted at the dental clinic of the Federal University of Amazonas, Manaus, Brazil, from December 2016 to September 2017, with patients needing endodontic treatment. Written consent was obtained from all individuals who participated in this clinical trial.

Sample size was calculated using $\mathrm{G}^{*}$ Power, version 3.1.9.2. A total of 78 patients would be required to achieve $90 \%$ power, with an $\alpha$ value of $5 \%$, and a difference of $30 \%$ in the prevalence of any postoperative pain between the control and experimental group, adopted based on the previous studies conducted by Rosenberg et al. (7) and Lopes et al. (5).

Men and women, aged 18-60 years, diagnosed with symptomatic irreversible pulpitis, without periapical diseases, with indication for endodontic treatment in molar teeth, except for third molars, and with teeth in occlusal contact only by tooth structure, were included $\dot{i}$ in the study. Diagnosis was confirmed by cold thermal testing. The cold spray (Endo-Frost; Coltene-Whaledent, Langenau, Germany) was applied on the occlusal surface of the molar for 5 second with the aid of a cotton swab. If the molar responded positively to the test, occlusal contact was confirmed with articulating paper for the tooth to be eligible for the study (Table 1).

Exclusion criteria included patients at any stage of

Table 1. Demographic and clinical data of recruited patients

\begin{tabular}{lccc}
\hline Variable & OAG $(\mathrm{n}=38)$ & CG $(\mathrm{n}=40)$ & $\mathrm{p}$-value \\
\hline Mean age & $29.7 \pm 9.0$ & $27.4 \pm 8.1$ & 0.238 \\
Gender & & & 0.749 \\
Men & $12(31.6 \%)$ & $14(35 \%)$ & \\
Women & $26(68.4 \%)$ & $26(65 \%)$ & \\
Extrusion of & & & 0.260 \\
material filling & & & \\
Yes & $17(44.7 \%)$ & $23(57.5 \%)$ & \\
No & $21(55.3 \%)$ & $17(42.5 \%)$ & \\
Systemic diseases & None & None & - \\
Preoperative pain (VRS) & $2.5 \pm 0.71$ & $2.3 \pm 0.47$ & 0.175 \\
\hline
\end{tabular}

pregnancy, who were on anti-inflammatory or antibiotic medication, immunocompromised, hypersensitive to anti-inflammatory drugs, presented previous diagnosis of bruxism or dental clenching, signs and symptoms of temporomandibular disorders, unrestorable teeth, coronal coverage, teeth with endodontic complications or any type of apical periodontitis or severe periodontal diseases, as any of these conditions could interfere with the analysis of the presence of pain after endodontic treatment.

The randomization process was performed using the Sealed Envelope ${ }^{\circledR}$ program (sealedenvelope.com - Exmouth House, London, UK) by a third researcher who was not involved in the research protocol. A list was generated for random allocation of the 78 subjects in the groups, stratified by sex, divided into 4 blocks. Each sequence of randomized numbers was individually placed in opaque, sealed, and sequentially numbered envelopes. After the endodontic protocol, the numbered envelope was opened by the operator to know in which group the patient would be allocated. Patients were unaware of their allocation.

Of the 162 patients considered eligible for the study, 84 did not meet the inclusion criteria. Thus, 78 patients participated in the study and they were divided into two groups: 38 patients in the occlusal adjustment group and 40 patients in the control group (Fig. 1).

\section{Endodontic Treatment Protocol}

The endodontic treatment protocol was based on work published by Lopes et al. (5) before endodontic treatment, clinical and periapical radiographic examination was carried out again to confirm the diagnosis of irreversible pulpitis as well as verification of occlusal contact with the aid of articulating paper. As preoperative pain is an important factor that can influence the outcome of the study, it was

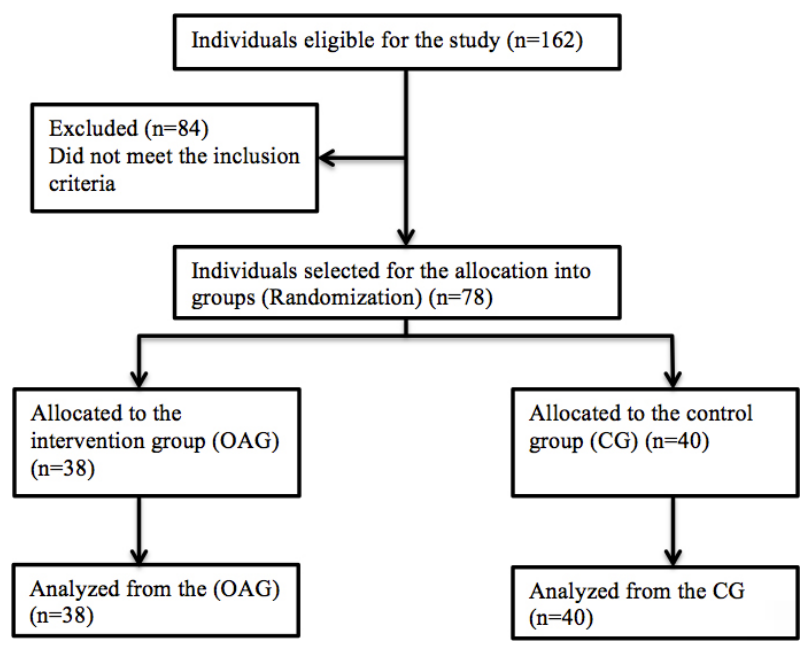

Figure 1 Flow diagram CONSORT for randomized clinical trials 
measured using the VRS scale to compose the baseline data. The patient was recruited only when the inclusion criterion was confirmed by the operator and after signing the informed consent (IC) form.

The endodontic treatment protocol consisted of anaesthesia with $3.6 \mathrm{~mL}$ of $2 \%$ lidocaine with epinephrine 1:100,000 (Alphacaine; DFL Indústria e Comércio Ltda, Rio de Janeiro, RJ, Brazil) by inferior alveolar nerve block or maxillary infiltration anaesthesia. After rubber dam placement, the pulp chamber was accessed with round burs.

A glide path was established with K-files \#10 and Proglider ${ }^{\circledR}$ rotary instruments (Denstply, Maillefer, Ballaigues, Switzerland). The working length was determined with the electronic apex locator (Novapex, Forum Technologies, Rishon Le-Zion, Israel) $0.5 \mathrm{~mm}$ from the apical foramen and confirmed by periapical radiographic examination.

Root canal instrumentation was performed with the WaveOne ${ }^{\circledR}$ Gold reciprocating system (Denstply, Maillefer, Ballaigues, Switzerland), in accordance with the manufacturer's recommendation. The instruments were driven by the XSmart Plus ${ }^{\circledR}$ motor (Denstply, Maillefer, Ballaigues, Switzerland) in reciprocating motion. If the size $10 \mathrm{~K}$-file was introduced with difficulty up to the middle third of the root canal, the small instrument (21.06) was selected. If the size $10 \mathrm{~K}$-file was passively introduced into the canal, the primary instrument (25.08) was selected; if the size $20 \mathrm{~K}$-file was passively introduced into the canal, the large instrument (40.08) was selected.

After selecting the instrument, it was introduced into the root canal with short movements between 3 and 4 $\mathrm{mm}$ in the apical direction, until complete instrumentation of the root canal. During preparation, the instruments were removed and cleaned with a gauze, followed by irrigation with 2.5\% sodium hypochlorite with the aid of a Max-i-Probe 30-G needle (Denstply, Maillefer, Ballaigues, Switzerland) up to $3 \mathrm{~mm}$ of the working length, which was measured by a silicone stop. Irrigation was performed with $10 \mathrm{~mL}$ of the solution for approximately five times during instrumentation.

A size $10 \mathrm{~K}$-file was used to verify patency in the working length in all root canals. After instrumentation, the teeth were irrigated with $1 \mathrm{~mL}$ of $17 \%$ EDTA prior to obturation. The root canals were then dried with sterile absorbent paper points (WaveOne ${ }^{\circledR}$ system) compatible with the root canal diameters.

Obturation of all teeth was performed with guttapercha cones (WaveOne ${ }^{\circledR}$ system). Periapical radiography was performed to confirm obturation limit. The cones were then introduced into the root canal with the sealer AH Plus ${ }^{\circledR}$ (Denstply, Maillefer, Ballaigues, Switzerland) in the first 5 $\mathrm{mm}$. All teeth were sealed using the thermocompaction technique with the aid of size 60 gutta condenser (Denstply, Maillefer, Ballaigues, Switzerland) up to $5 \mathrm{~mm}$ short of the working length.

After obturation, temporary coronary sealing was performed with glass ionomer sealer followed by final radiography. The endodontic treatment protocol was performed in the same way in both groups. At the completion of endodontic treatment, the numbered, sealed, randomization envelope was opened by the operator and patient allocation was revealed.

\section{Intervention Protocol}

At the position of maximum habitual intercuspation and also at dynamic mandibular movement, occlusal contact was marked with the aid of articulating paper. In the occlusal adjustment group, functional and nonfunctional occlusal contacts on the cusps or marginal ridges were removed with a high-speed diamond bur (3118F, KG Sorensen, Cotia, São Paulo, Brazil) under cooling.

In the control group, after identification of occlusal contacts, adjustment was simulated using a high-speed hand piece with a smooth, non-cutting tip under abundant cooling for blinding effect.

The patients received postoperative guidelines and instructions on how their evolution would be assessed during the previously scheduled telephone interviews.

\section{Assessment of Postoperative Pain}

The assessment of postoperative pain was performed by a researcher-examiner blinded to the treatments. The primary outcome was the prevalence of postoperative pain in each group. The NRS and VRS were applied at 6, 24 and $72 \mathrm{~h}$ after endodontic treatment (Fig. 2).

The patient could address the operator in case of doubts at any time. In cases of moderate or severe pain, the patient was advised to administer anti-inflammatory medication (Ibuprofen 600mg every $8 \mathrm{~h}$ for 3 days). Patients did not

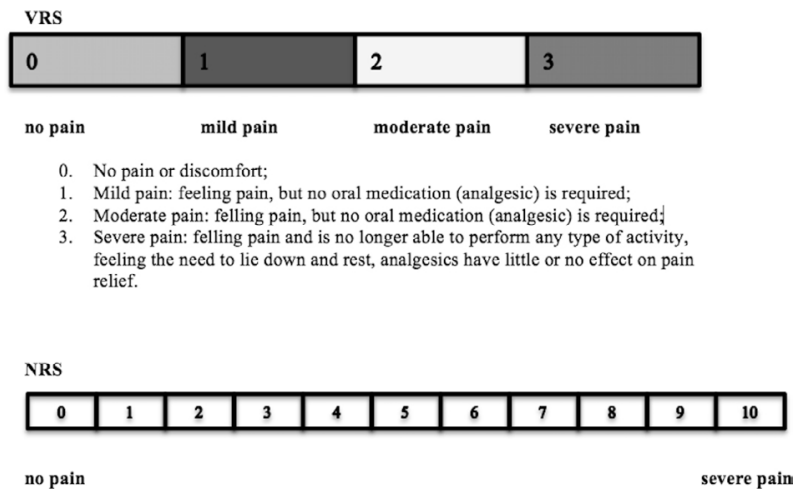

Figure 2 Verbal rating scale (VRS) and Numerical rating scale (NRS) used in the study 
have to return for follow-up evaluation, as they were contacted by telephone. First, the researcher asked the patient to rate pain using the verbal rating scale and then to rank the symptom on the numerical scale from 0 to 10 .

\section{Statistical Analysis}

The demographic and clinical characteristics of the individuals included in each study group were described. Continuous variables were described by mean and standard deviation and categorical variables by absolute and relative frequencies.

The evolution of postoperative pain throughout the study was also demonstrated by means of line charts. The proportion of individuals with pain was compared by chi-squared and Fisher's exact tests $(p<0.05)$. Multiple nonparametric regression analyzes for the outcomes of postoperative pain at $6 \mathrm{~h}, 24 \mathrm{~h}$ and $72 \mathrm{~h}$ were also performed to evaluate the intervention without the effect of possible confounding.

The comparison of pain scores between the two groups at each time interval was performed using Mann-Whitney test (Wilcoxon rank-sum) for non-parametric data $(p<0.05)$. - The evolution of pain within each group was assessed by the paired Wilcoxon test. T-tests were further carried out to contribute to the discussion about probability of a type II error in non-parametric analysis. All analyses were performed in software Stata/IC, version 15 (StataCorp, TX).

\section{Results}

In the occlusal adjustment group, 71.1\% $(n=27)$ of the individuals reported postoperative pain and $67.5 \%$ $(n=27)$ in the control group. The number of individuals who reported pain as well as pain intensity decreased over the period analyzed.

Twenty-one individuals in the occlusal adjustment group and 24 individuals in the control group reported

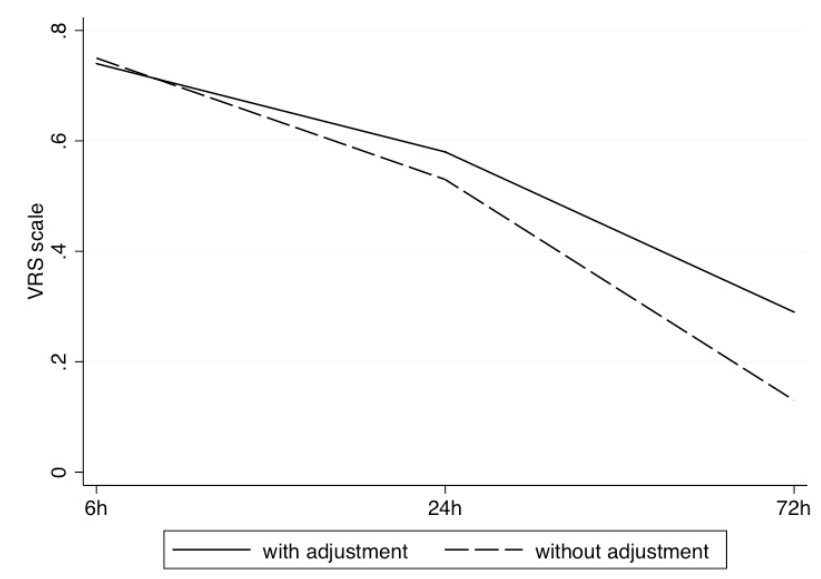

Figure 3 Evolution of pain on the VRS pain within $6 h(p=0.672)$. After $24 h, 18$ and 19 individuals reported pain $(p=0.991)$ and 8 and 4 individuals reported pain after $72 \mathrm{~h}(\mathrm{p}=0.219)$, respectively.

There were no statistically significant differences in the intensity of postoperative pain between the groups after $6 \mathrm{~h}$ (VRS, $p=0.719, N R S, p=0.547), 24 \mathrm{~h}$ (VRS, $p=0.906$, NRS, $p=0.987)$ and $72 \mathrm{~h}$ (VRS, $p=0.178$; NRS, $p=0.176$ ) on both the VRS and NRS. The mean values of the scales at each time are shown in Figure 3,4 and Table 2. Only one patient reported taking postoperative medication (lbuprofen 600mg). Extrusion of filling material also had no relation with postoperative pain in the three evaluated times [VRS, $p=1.000$ (6h), $p=0.588$ (24h), $p=0.150$ (72h); NRS, $p=0.878$ (6h), $p=0.559$ (24h), $p=0.120$ (72h)]. Table 3 shows the adjusted effects of multiple regression analyzes confirming the non-significant effect of the intervention on postoperative pain.

The reduction of pain scores on both scales was significant for both groups between $6 h$ and $72 h(p<0.001)$. However, pain reduction between $6 \mathrm{~h}$ and $24 \mathrm{~h}$ was significant only for the group without occlusal adjustment (VRS, $p=0.031$, NRS, $p=0.008$ ). Stratified analysis according to intervention and extrusion of material filling did not influence the results at 6-72h interval, but at 6-24h pain reduction in group without occlusal adjustment was observed only among individuals without material extrusion (VRS, $p=0.033$, NRS, $p=0.028$ ). All the results obtained through t-tests were similar.

Only one patient (control group) reported taking postoperative medication (lbuprofen) for $24 \mathrm{~h}$. The results did not differ when the data were reanalyzed without the inclusion of this patient.

\section{Discussion}

It was postulated that aggression to the periapical tissues, originating from pulp pathology or endodontic

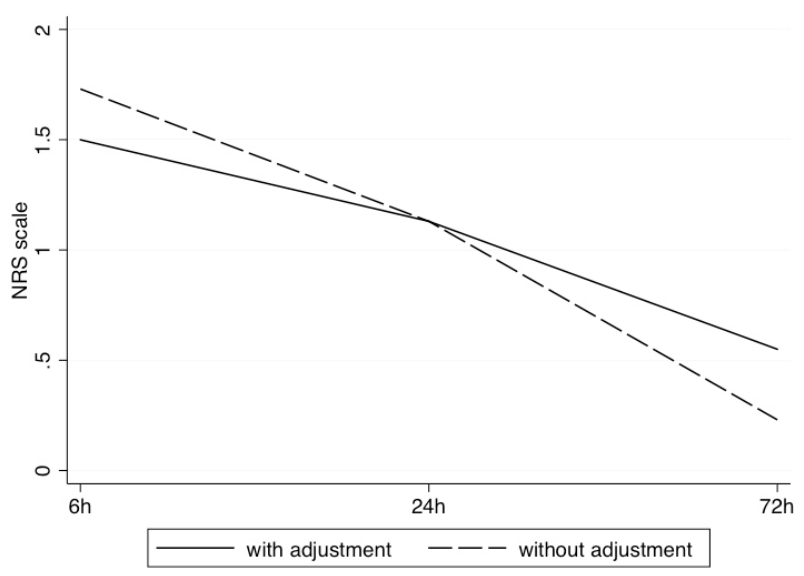

Figure 4 Evolution of pain on the NRS 
treatment, would result in the release of chemical mediators, sensitization of voltage-regulated sodium channel molecules and nociceptors, causing a change in the response pattern, among them mechanical allodynia, which is caused by non-painful stimuli. Mechanical allodynia is defined as a reduction in pain threshold, with pain occurring in response to innocuous thermal and mechanical stimuli (15-19).

However, the incidence of occlusal forces after endodontic treatment does not seem to influence the occurrence of postoperative pain when the physiological occlusion of the patient is maintained, which is in

Table 2. Primary outcomes of prevalence of postoperative pain mean $( \pm \mathrm{SD})$

\begin{tabular}{lccc}
\hline & \multicolumn{3}{c}{ VRS } \\
\cline { 2 - 4 } & $6 \mathrm{~h}$ & $24 \mathrm{~h}$ & $72 \mathrm{~h}$ \\
\hline $\begin{array}{l}\text { With } \\
\text { adjustment }\end{array}$ & $0.74(0.83)$ & $0.58(0.72)$ & $0.29(0.65)$ \\
$\begin{array}{l}\text { Without } \\
\text { adjustment }\end{array}$ & $0.75(0.71)$ & $0.53(0.60)$ & $0.13(0.40)$ \\
& & $\mathrm{NRS}$ & \\
& $6 \mathrm{~h}$ & $24 \mathrm{~h}$ & $72 \mathrm{~h}$ \\
$\begin{array}{l}\text { With } \\
\text { adjustment }\end{array}$ & $1.50(1.75)$ & $1.13(1.49)$ & $0.55(1.33)$ \\
$\begin{array}{l}\text { Without } \\
\text { adjustment }\end{array}$ & $1.73(1.83)$ & $1.13(1.44)$ & $0.23(0.77)$ \\
\hline
\end{tabular}

Table 3. Multiple nonparametric regressions for the outcomes of postoperative pain, adjusted effect estimates ( $p$-values)

\begin{tabular}{lccc}
\hline & \multicolumn{3}{c}{ VRS } \\
\cline { 2 - 4 } & $6 \mathrm{~h}$ & $24 \mathrm{~h}$ & $72 \mathrm{~h}$ \\
\hline $\begin{array}{l}\text { Group (ref.: without } \\
\text { adjustment) }\end{array}$ & $0.01(0.958)$ & $0.13(0.423)$ & $0.21(0.099)$ \\
$\begin{array}{l}\text { Gender (ref.: female) } \\
\text { Extrusion of material } \\
\text { filling (ref.: no) }\end{array}$ & $-0.31(0.094)$ & $-0.40\left(0.001^{* *}\right)$ & $-0.26\left(0.011^{*}\right)$ \\
Age & $-0.02(0.922)$ & $0.19(0.217)$ & $0.22(0.058)$ \\
& $6 \mathrm{~h}$ & $-0.02(0.076)$ & $-0.01(0.161)$ \\
& $-0.17(0.635)$ & $0.10(0.672)$ & $0.42(0.086)$ \\
$\begin{array}{l}\text { Group (ref.: without } \\
\text { adjustment) }\end{array}$ & $-0.89\left(0.026^{*}\right)$ & $-0.91\left(0.010^{*}\right)$ & $-0.53\left(0.011^{*}\right)$ \\
$\begin{array}{l}\text { Gender (ref.: female) } \\
\begin{array}{l}\text { Extrusion of material } \\
\text { filling (ref.: no) }\end{array}\end{array}$ & $-0.23(0.581)$ & $0.32(0.353)$ & $0.33(0.225)$ \\
Age & $-0.02(0.390)$ & $-0.03(0.180)$ & $-0.02(0.210)$ \\
\hline
\end{tabular}

Effect estimates are averages of derivatives for continuous covariates and averages of contrasts for factor covariates

${ }^{*} \mathrm{p}<0.05,{ }^{* *} \mathrm{p}<0.01$ agreement with the results found by Jostes and Holland (6), Parirokh et al.(8) and Arslan et al.(9).

Another justification for this finding may be the phenomenon of impulse deceleration and parallel sensory adaptive response, which is the inactivation of some isoforms of sodium channels caused by the great activity of these channels in the sensitized tissue, which results in the reduction of the impulse affecting the activation of mechanically sensitive nerve fibers, such as type $\mathrm{C}$ fibers. The biophysical process underlying the deceleration of the impulse leads to an increase in the mechanical threshold and probably results in decreased pain perception (20-22).

There are few studies on the influence of occlusal adjustment on postoperative pain after endodontic treatmentand they present few comparable criteria, which makes it difficult to understand the role of occlusal adjustment in pain prevention and control.The study by Jostes and Holland (6) found that occlusal adjustment did not influence patient comfort within six (6) days following endodontic instrumentation. The authors included 58 posterior teeth diagnosed with different pulp and periapical pathologies with indication for endodontic treatment. Endodontic instrumentation was performed by several operators and the technique used was not reported. The authors reported failure to detect variables that could hinder or reduce discomfort due to the limited number of individuals and the large number of variables.

The study by Rosenberg et al. (7) found that occlusal adjustment could prevent postoperative pain after endodontic instrumentation in teeth with pulp vitality. The limitations of the study included selection bias, confounders, and limited information about randomization. In addition, the molars presented different pulp and periapical pathologies and the endodontic protocol was performed using the step-back technique with the aid of manual instruments, and patients with bruxism were included in the study.

The study by Arslan et al. (9) did not find any statistically significant differences between the groups with semi-adjustment,complete, and without occlusal adjustment after 1, 3, 5, and 7 days regarding thelevels of postoperative pain levels after endodontic treatment. The study was the only one to assess pain after root canal obturation, it included a sample of 35 molars diagnosed with symptomatic apical periodontitis and single-visit treatment was performed using the ProTaper ${ }^{\circledR}$ rotating system (Dentsply Maillefer, Ballaigues, Switzerland). The study used computerized occlusal analysis system (T-Scan II) to quantify force exerted on the endodontically treated tooth. 
Differing results may be explained by the influence of preoperative pain on the outcome of studies $(7,23)$. The results of this study also differ from those of Emara et al. (24) who detected differences in postoperative pain levels after endodontic treatment in the occlusal reduction group, which can explain the high levels of preoperative pain in the sample and may exacerbate the allodynia phenomenon.

The mean postoperative pain rates in this study are low in comparison with previous studies, which is explained by the study design as it involves the standardization of the dental group, moderate preoperative pain rate, and singlesession endodontic protocol with a single operator. Similar results were observed in the studies of Relvas et al. (4) and Lopes et al. (5) using similar protocols.

One point to be discussed is the method for recording occlusion. Traditionally, occlusion analysis is performed with articulating paper marking the contacts. Recently, computerized occlusal analysis has been used in scientific studies with the purpose of tracing the distribution of forces of occlusion using pressure-sensitive sheets, which is not possible in daily clinical situations using conventional methods. However, this method does not produce any contact markings intraorally for posterior $\approx$ adjustment of occlusion and it has been demonstrated that a combination of methods of computerized occlusion analysis with marking foils would be ideal, which would be marked intraorally with an even higher accuracy $(9,16)$.

Pain assessment was performed using verbal and numerical scales. According to Williamson and Hoggart (25), patients prefer the verbal rating scale because it is simple, but it is the least sensitive of the scales. The numerical rating scale is more efficient, relatively easy to interpret, and it has greater statistical sensitivity. The protocol of using two scales was also adopted in the study by Lopes et al. (5).

In this clinical study, both scales presented similar values and showed no statistically significant difference in the evaluation within 6, 24 and $72 \mathrm{~h}$ after endodontic treatment. The choice of these pain scales was due to their efficiency and ease of evaluation through telephone calls, thus avoiding the need for a second session.

Among the limitations of this study are the inclusion of men and women and a wide window of ages (18-60 years). To eliminate this effect, patients were randomized to ensure comparability between the groups. Another factor is the difficulty in evaluating subjective aspects, such as pain and the presence of other factors that may influence the presence and intensity of pain. In order to minimize this effect, clarifications were provided about pain assessment and the instruments were applied by a single researcher-examinerusing a standardized approach.

Regarding baseline factors such as gender, age, overfilling and preoperative pain, the nonparametric multiple regression analyzes showed no evidence that these factors were confounding. The well-executed randomization of the patients ensured that these variables were equally distributed among the groups and not considered confounding factors.

Future research should include occlusal surface reduction prior to root canal treatment has been advocated to prevent postoperative pain in teeth; however, randomized clinical trials are scarce, which makes it difficult to consolidate clinical protocols that preserve tooth structures. Studies like this should be done on teeth with necrotic pulp with apical periodontitis, periapical lesions represent an increased risk for postoperative pain (26).

In the present study, occlusal adjustment did not influence the prevalence of postoperative pain of endodontically treated teeth with symptomatic irreversible pulpitis.

\section{Resumo}

0 objetivo deste estudo prospectivo, randomizado e clínico foi analisar a influência do ajuste oclusal na prevalência de dor pós-operatória após o tratamento endodôntico. Setenta e oito pacientes, diagnosticados com pulpite irreversivel sintomática com indicação de tratamento endodôntico, foram selecionados para participar do estudo. Os participantes foram randomizados e divididos em dois grupos: no grupo de ajuste oclusal (GAO), foi realizado tratamento endodôntico com posterior ajuste oclusal. No grupo controle (GC), o tratamento endodôntico foi realizado sem ajuste oclusal. Os tratamentos foram realizados pelo mesmo operador. A ocorrência e a intensidade da dor foram registradas em duas escalas: a escala de classificação verbal (VRS) e a escala de classificação numérica (NRS). A avaliação da dor foi realizada por um segundo examinador, cego para o experimento, 6, 24 e 72 horas após o tratamento endodôntico. Os dados foram analisados utilizando testes de Mann-Whitney, qui-quadrado e exato de Fisher. No grupo de ajuste oclusal, 71,1\% relataram dor pósoperatória e 67,5\% relataram dor no grupo controle. Na avaliação de 6 horas, 21 indivíduos relataram dor no grupo de ajuste oclusal e 24 no grupo controle $(p=0,672)$. Na avaliação de 24 horas, 18 e 19 individuos relataram dor $(p=0,991)$ e, na avaliação de 72 horas, 8 e 4 relataram dor $(p=0,219)$, respectivamente. 0 ajuste oclusal não influenciou a prevalência de dor pós-operatória após o tratamento endodôntico em dentes com pulpite irreversivel sintomática.

\section{Acknowledgments}

The authors thank the public funding agencies: Coordination of Improvement of Higher Education Personnel of the Ministry of Education (CAPES) and Foundation for Research Support of the State of Amazonas (FAPEAM) for their support to the Master course in Dentistry of Federal University of Amazonas.

\section{References}

1. Sathorn $C$, Parashos $P$, Messer $H$. The prevalence of postoperative pain and flare-up in single- and multiple-visit endodontic treatment: a systematic review. Int Endod J 2008;41:91-99.

2. Silva EJ, Menaged K, Ajuz N, Monteiro MR, Coutinho-Filho Tde S. Postoperative pain after foraminal enlargement in anterior teeth with necrosis and apical periodontitis: a prospective and randomized clinical Trial. J Endod 2013;39:173-176.

3. Nekoofar MH, Sheykhrezae MS, Meraji N, Jamee A, Shirvani A, Jamee $\mathrm{J}$, et al. Comparison of the effect of root canal preparation by using 
WaveOne and ProTaper on postoperative pain: a randomized clinical trial. J Endod 2015;41:575-578.

4. Relvas JB, Bastos MM, Marques AA, Garrido AD, Sponchiado EC JR. Assessment of postoperative pain after reciprocating or rotary NiTi instrumentation of root canals: a randomized, controlled clinical trial. Clin Oral Investig 2016;20:1987-1993.

5. Lopes LPB, Herkrath FJ, Vianna ECB, Gualberto Junior EC, Marques $A A F$, Sponchiado Junior EC. Effect of photobiomodulation therapy on postoperative pain after endodontic treatment: a randomized, controlled, clinical study. Clin Oral Investig 2019;23:285-292.

6. Jostes JL, Holland GR. The effect of occlusal reduction after canal preparation on patient comfort. J Endod 1984;10:34-37.

7. Rosenberg PA, Babick PJ, Schertzer L, Leung A. The effect of occlusal reduction on pain after endodontic instrumentation. J Endod 1998;24:492-496.

8. Parirokh M, Rekabi AR, Ashouri R, Nakhaee N, Abbott PV, Gorjestani $\mathrm{H}$. Effect of occlusal reduction on postoperative pain in teeth with irreversible pulpitis and mild tenderness to percussion. J Endod 2013;39:1-5

9. Arslan H, Seckin F, Kurklu D, Karatas E, Yanikoglu N, Capar ID. The effect of various occlusal reduction levels on postoperative pain in teeth with symptomatic apical periodontitis using computerized analysis: a prospective, randomized, double-blind study. Clin Oral Investig 2017;21:857-863.

10. Pak JG, White $\mathrm{S}$. Pain prevalence and severity before, during, and after Root Canal Treatment: a systematic review. J Endod 2011;37:429-438.

11. Ramamoorthi S, Nivedhitha MS, Divyanand MJ. Comparative evaluation of postoperative pain after using endodontic needle and Endo Activator during root canal irrigation: a randomised controlled trial. Aust Endod J 2015;41:78-87.

12. Arora $M$, Sangwan $P$, Tewari $S$, Duhan J. Effect of maintaining apical patency on endodontic pain in posterior teeth with pulp necrosis and apical periodontitis: a randomized controlled Trial. Int Endod J 2016;49:317-324.

13. Shahi $S$, Asghari $V$, Rahimi $S$, Lotfi $M$, Samiei $M$, Yavari $H$, et al. Postoperative pain after endodontic treatment of asymptomatic teeth using rotary instruments: a randomized clinical trial. Iran Endod J 2016;11:38-43.

14. Khan $A A$, Owatz $C B$, Schindler WG, Schwartz SA, Keiser K, Hargreaves $\mathrm{KM}$. Measurement of mechanical allodynia and local anesthetic efficacy in patients with irreversible pulpitis and acute periradicular periodontitis. J Endod 2007:33:796-799.

15. Owatz $C B$, Khan AA, Schindler WG, Schwartz SA, Keiser K, Hargreaves $\mathrm{KM}$. The incidence of mechanical allodynia in patients with irreversible pulpitis. J Endod 2007;33:552-556.

16. Koos B, Godt A, Schille C, Göz G. Precision of an instrumentation-based method of analyzing occlusion and its resulting distribution of forces in the dental arch. J Orofac Orthop 2010;71:403-410.

17. Atbaei, A, Mortazavi N. Prophylactic intraligamentary injection of piroxicam (feldene) for the management of post-endodontic pain in molar teeth with irreversible pulpitis. Aust Endod J 2012;138:31-35.

18. Gotler M, Bar-Gil B, Ashkenazi M. Postoperative pain after root canal treatment: a prospective cohort study. Int J Dent 2012;2012:310467.

19. Grga D, Dzeletović B, Damjanov M, Hajduković-Dragojlović L. Prostaglandin E2 in apical tissue fluid and postoperative pain in intact and teeth with large restorations in two endodontic treatment visits. Srp Arh Celok Lek 2013;141:17-21.

20. Baker MD, Waxman SG. Sodium channel slow inactivation and adaptation in C-fibres. J Physiol 2012;590:1513-1514.

21. De Col R, Messlinger K, Carr RW. Repetitive activity slows axonal conduction velocity and concomitantly increases mechanical activation threshold in single axons of the rat cranial dura. J Physiol 2012;590:725-736

22. Dickie AC, McCormick B, Lukito V, Wilson $\mathrm{KL}$, Torsney C. Inflammatory Pain Reduces C Fiber Activity-Dependent Slowing in a Sex-Dependent Manner, Amplifying Nociceptive Input to the Spinal Cord. J Neurosci 2017;37:6488-6502.

23. Creech $\mathrm{JL}$, Walton RE, Kaltenbach R. Effect of occlusal relief on endodontic pain. J Am Dent Assoc 1984;109:64-67.

24. Emara RS, Abou HM, Nasr EL, Boghdadi EL. Evaluation of postoperative pain intensity following occlusal reduction in teeth associated with symptomatic irreversible pulpitis and symptomatic apical periodontitis: a randomized clinical study. Int Endod J 2019;52:288-296.

25. Williamson A, Hoggart B. Pain: a review of three commonly used pain rating scales. J Clin Nurs 2005;14:798-804.

26. Siqueira JF Jr, Rôças IN, Favieri A, Machado AG, Gahyva SM, Oliveira $\mathrm{JC}$, et al. Incidence of post- operative pain after intracanal procedures based on an antimicrobial strategy. J Endod 2012;28:457-460

Received November 12, 2019 Accepted February 18, 2020 